\title{
Therapeutic Treatment with Sustained-Release Platelet-Rich Plasma Restores Blood Perfusion by Augmenting Ischemia-Induced Angiogenesis and Arteriogenesis in Diabetic Mice
}

\author{
Shyamal Chandra Bir ${ }^{c}$ Jiro Esaki ${ }^{a} \quad$ Akira Marui $^{a}$ Hisashi Sakaguchi ${ }^{a}$ \\ Christopher G. Kevilc Tadashi Ikeda ${ }^{\mathrm{c}}$ Masashi Komeda ${ }^{\mathrm{a}}$ Yasuhiko Tabata ${ }^{\mathrm{b}}$ \\ Ryuzo Sakata ${ }^{a}$ \\ a Department of Cardiovascular Surgery, Graduate School of Medicine, and 'bepartment of Biomaterials, \\ Field of Tissue Engineering, Institute for Frontier Medical Sciences, Kyoto University, Kyoto, Japan; \\ 'Department of Pathology, LSU Health Sciences Center, Shreveport, La., USA
}

\section{Key Words}

Diabetes • Ischemia • Angiogenesis • Growth factors •

Platelet-rich plasma

\begin{abstract}
Objective: The objective of this investigation was to establish the effectiveness of sustained-release platelet-rich plasma (PRP) on perfusion and neovascularization in diabetic murine hind limb ischemia. Methods: After surgery in streptozotocin-induced diabetic mice, the mice were randomly assigned to the following 4 experimental groups: control (C), $100 \mu \mathrm{l}$ of the sustained-release form of platelet-poor plasma (PPP), $100 \mu \mathrm{l}$ of the solution form of PRP (PRP-sol), and $100 \mu \mathrm{l}$ of the sustained-release form of PRP (PRP-sr). Endpoint evaluations were: blood perfusion by laser Doppler perfusion imaging (LDPI), vascular density by anti-vWF, and mature vessel density by anti-smooth muscle actin antibody. $\boldsymbol{R} \boldsymbol{e}$ sults: This study demonstrated that a sustained release of PRP increases the perfusion of ischemic tissue as measured by LDPI $(57 \pm 12 ; 56 \pm 9 ; 72 \pm 7$, and $98 \pm 4$ for the C, PPP, PRP-sol, and PRP-sr groups, respectively; $\mathrm{p}<0.05)$, capillary density $(151 \pm 16 ; 158 \pm 12 ; 189 \pm 39$, and $276 \pm 39$ for
\end{abstract}

groups C, PPP, PRP-sol, and PRP-sr, respectively; $\mathrm{p}<0.05)$, and mature vessel density $(28 \pm 2 ; 31 \pm 3 ; 52 \pm 10$, and $85 \pm 13$ for the C, PPP, PRP-sol, and PRP-sr groups, respectively; $\mathrm{p}<$ 0.05). Conclusion: A sustained release of PRP containing potent angiogenic growth factors restores blood perfusion by stimulating angiogenesis and arteriogenesis.

Copyright $\odot 2010$ S. Karger AG, Basel

\section{Introduction}

Peripheral arterial disease (PAD) is a cardiovascular disorder whose prevalence is rising with the recent increase in the proportion of geriatric and diabetic populations around the world. Therapeutic angiogenesis remains an attractive treatment modality for PAD and chronic tissue ischemia. Numerous mediators, including growth factors, transcription factors, and signaling molecules have been reported to augment chronic ischemiainduced angiogenesis in animal models. However, clinical trials of single and the solution form of proangiogenic agents have little-to-no practical utility in patients with such a disorder [1]. Therefore, there remains a clear need

\section{KARGER}

Fax +41613061234 E-Mail karger@karger.ch www.karger.com
(C) 2010 S. Karger AG, Basel

$1018-1172 / 11 / 0483-0195 \$ 38.00 / 0$

Accessible online at:

www.karger.com/jvr
Prof. Ryuzo Sakata

Department of Cardiovascular Surgery

Graduate School of Medicine, Kyoto University

54 Kawaharacho, Shogoin, Sakyo-ku, Kyoto 606-8507 (Japan)

Tel. +81 75751 3780, Fax +81 75751 3098, E-Mail sbir@lsuhsc.edu 
for better interventions with which to induce therapeutic angiogenesis.

Neovascularization is now believed to occur via 3 possible mechanisms: the sprouting of preexisting resident endothelial cells (angiogenesis), maturation and enlargement of the preexisting small vessels through vascular remodeling (arteriogenesis), and the recruitment of bone marrow-derived endothelial progenitor cells (vasculogenesis). Among the above mentioned approaches, therapeutic angiogenesis with growth factors constitutes a potential alternative approach for patients with PAD and for improving the neovascularization of ischemic tissues [2]. The establishment of stable and functional blood vessel networks, however, is a complex process that requires several angiogenic factors to stimulate vessel sprouting and the remodeling of the primitive vascular network [3-5].

Furthermore, diabetes mellitus (DM) is one of the negative predictors of neovascularization. There is increasing evidence that all of the processes of neovascularization, such as angiogenesis, arteriogenesis, and vasculogenesis, are impaired in diabetic ischemia which demands more attention to the interplay between different growth factors as well as cells [6-10].

In relation to the above mentioned issues PRP, i.e. a limited volume of plasma rich in platelets, is attracting attention as a safe and cost-effective source of various growth factors $[11,12]$. It also induces VEGF and HGF in culture [12]. By containing these various cytokines, PRP plays important roles in regenerating damaged tissue [13, 14]. However, little is known about the mechanism of the PRP-related regeneration of diabetic ischemic tissues.

A short shelf life and an inefficient delivery to target cells are major concerns associated with the local administration of recombinant human growth factors. The growth factor is expensive and many doses may be required to achieve any therapeutic effect, especially with the solution form. In light of these limitations, we have reported the efficacy of gelatin hydrogel microspheres as a carrier for the local, slow, and sustained delivery of different growth factors $[9,15,16]$. Furthermore, we have also reported that gelatin hydrogel is a promising carrier for the growth factors in PRP $[11,17]$.

The objective of this investigation was to characterize the angiogenic and growth factor content of diabetic PRP and to determine, in vitro, its effect on endothelial cell proliferation and capillary tube formation. Additionally, this experiment sought to determine the effectiveness of different compositions of PRP (solution vs. sustained release) on perfusion and neovascularization in a diabetic murine model of hind limb ischemia.

\section{Methods}

\section{Experimental Animals}

Six-week-old male C57BL/6 mice were purchased from Japan SLC (Shizuoka, Japan). The Kyoto University Animal Experiment Committee approved the experiment protocol. Animals were cared for in compliance with the Guide for the Care and Use of Laboratory Animals, Institute of Laboratory Animal Resources, Commission on Life Sciences, National Research Council.

\section{Generation of the Diabetic Model}

Six-week-old male C57BL/6 mice were randomized to receive an intraperitoneal injection of streptozotocin (STZ; $150 \mathrm{mg} / \mathrm{kg} /$ dose) dissolved in $1 \mathrm{M}$ sodium citrate buffer, $\mathrm{pH} 4.5$, or vehicle to generate the diabetic model. Two weeks after injection, the serum glucose level was measured using an Accu-Chek II Advantage Glucometer (Roche Diagnostics, Basel, Switzerland). Mice with serum glucose levels $\geq 250 \mathrm{mg} / \mathrm{dl}$ were included in this study [9]. This blood sugar level (>250 mg/dl) was consistently maintained during the whole study period.

\section{Preparation of PRP and Platelet-Poor Plasma ( $P P P)$}

Peripheral blood $(10 \mathrm{ml})$ was collected from STZ-induced diabetic mice using an anticoagulant citrate-phosphate-dextrose solution. The collected blood was centrifuged at 2,400 rpm/10 $\mathrm{min} / 20^{\circ} \mathrm{C}$; the supernatant (plasma) including the buffy coat and content $0.5 \mathrm{ml}$ below the buffy coat was decanted to the other tube and RBC and WBC were discarded. Secondary centrifugation was performed at $3,600 \mathrm{rpm} / 10 \mathrm{~min} / 20^{\circ} \mathrm{C}$. The clear supernatant (plasma) was decanted until $0.5 \mathrm{ml}$ was left and the middle portion of the supernatant (plasma) was taken as PPP. Finally, the remaining supernatant including the buffy coat and content 0.5 $\mathrm{ml}$ below the buffy coat was taken as PRP and stored at $-80^{\circ} \mathrm{C}$ for various evaluations. The quantification of platelets in PRP was done by Falco Laboratory, Kyoto, Japan [11].

\section{Preparation of Gelatin Hydrogel Microspheres}

\section{Containing PRP}

PRP contains different cytokines but these cytokines, having a faster degradation, are effective for a very short time. Our previous studies have shown that when platelets in PRP are activated with gelatin molecules during the process of PRP impregnation, growth factors are released from the PRP. The growth factors secreted are immobilized in the hydrogel through physicochemical interaction with gelatin molecules. The immobilized growth factors are released from the hydrogel as a result of hydrogel degradation [17]. We have also developed a sustained-release form for the many growth factors and have shown that the sustained release of these growth factors incorporated in gelatin hydrogel microspheres effectively restores revascularization in different models of cardiovascular disease $[9,16]$. Therefore, we used gelatin hydrogel as a carrier for the growth factors in the PRP.

Gelatin hydrogel microspheres incorporating PRP were prepared as described previously $[9,11,16,17]$. Briefly, gelatin with an isoelectric point of 4.9 was isolated from bovine bone collagen by an alkaline process using $\mathrm{Ca}(\mathrm{OH})_{2}$ (Nitta Gelatin, Osaka, Japan). Gelatin microspheres were prepared through (1) the cross linking of gelatin in aqueous solution dispersed in an oil phase and (2) the cross linking of gelatin microspheres with glutaraldehyde. Microsphere diameter was measured for at least 100 micro- 
spheres by viewing with a light microscope to calculate their volume. The average diameter of the freeze-dried microspheres was $26 \mu \mathrm{m}$.

PRP and PPP were incorporated into the gelatin microspheres by dropping $100 \mu \mathrm{l}$ of PRP or $100 \mu \mathrm{l}$ of PPP solution into $10 \mathrm{mg}$ of freeze-dried gelatin microspheres, respectively, which were then left in an incubator for $1 \mathrm{~h}$ at $37^{\circ} \mathrm{C}$ temperature. The solution $(100 \mu \mathrm{l})$ was completely absorbed into the microspheres during swelling since the solution volume was less than that theoretically required for the equilibrated swelling of microspheres. Upon use, the PRP containing gelatin hydrogel microspheres was dispersed in $100 \mu \mathrm{l}$ of PBS, aspirated into a 1-ml syringe attached to a 27-gauze needle (Terumo, Tokyo, Japan), and applied via a single intramuscular injection to the ischemic site.

\section{Measurement of Different Growth Factors Using}

\section{Enzyme-Linked Immunosorbant Assay}

The concentrations of different growth factors such as stromal cell-derived factor $1-\alpha$ (SDF-1 $\alpha)$, platelet-derived growth factor $\mathrm{BB}$ (PDGF-BB), vascular endothelial growth factor (VEGF), basic fibroblast growth factor (bFGF), and insulin-like growth factor-1 (IGF-1) in PRP and PPP were quantified using enzyme-linked immunosorbent assay (ELISA) methods (R\&D Systems, USA). The analyses were then performed as instructed by the manufacturer. Briefly, samples and standards were added to 96 growth factor antibody-coated well plates. After incubation and the removal of unbound substances, a secondary antibody was added. This step was followed by a further washing and incubation with a substrate. The color reaction was stopped and optical density measured at the wavelength of $495 \mathrm{~nm}$ [11].

\section{Endothelial Cell Proliferation Assay}

Mouse MSS31 endothelial cells (MSS31 was a kind gift from Dr. Kenichi Yamahara MD, PhD, Osaka National Heart Center, Osaka, Japan) were cultured on $\alpha$-MEM medium supplemented with 10\% fetal bovine serum (FBS) and antibiotics (Nacalai Tesque, Inc., Kyoto, Japan). Cultures were maintained at $37^{\circ} \mathrm{C}, 5 \%$ $\mathrm{CO}_{2}$, and $100 \%$ humidity.

The endothelial cell proliferation assay was performed as follows: endothelial cells were plated in human plasma fibronectincoated 24-well culture plates at a density of $3 \times 10^{4}$ cells/well in $\alpha$-MEM medium containing $10 \%$ FBS and cultured at $37^{\circ} \mathrm{C}$. The next day, the medium was changed to $\alpha$-MEM medium containing $0.5 \%$ FBS with or without PRP, and culture was continued for 3 days. Cells were detached with trypsin and counted using a hemocytometer $[11,18]$.

\section{Tube Formation Assay}

Growth factor reduced Matrigel (BD Biosciences) was used to coat the wells of 24 -well plates $(0.20 \mathrm{ml} /$ well $)$ and was left to polymerize at $37^{\circ} \mathrm{C}$ for $30 \mathrm{~min}$. MSS31 endothelial cells suspended in $\alpha$-MEM medium supplemented only with $0.5 \%$ FBS and antibiotics were added to each well after polymerization. Subsequently, PRP was added to the selected well and incubated for 6-8 h. The medium was removed and the cells were fixed with $4 \%$ paraformaldehyde. Photographs were taken through a microscope (Olympus, Tokyo, Japan). The capillary tube area was quantified per square micrometer using image analysis software (Image Corporation) $[11,18]$.

\section{Mouse Ischemic Hind Limb Model}

Hind limb ischemia was created in the 6-week-old male wildtype mice as described previously $[9,11,16]$. Briefly, after the mice were anesthetized using intraperitoneal sodium pentobarbital (60 $\mathrm{mg} / \mathrm{kg}$ ), the entire right saphenous artery and vein, the right external iliac artery and vein, and the deep femoral and circumflex arteries and veins were ligated, cut, and excised to obtain a mouse model of severe hind limb ischemia as described previously.

After surgery, the mice were randomly assigned to 4 experimental groups ( $\mathrm{n}=10$, each group) and treated for 4 weeks as follows: $10 \mathrm{mg}$ gelatin hydrogel microspheres only (control group), sustained-release form of PPP (100 $\mu \mathrm{lPPP} / 10 \mathrm{mg}$ gelatin hydrogel microspheres, PPP group), $100 \mu l$ solution form of PRP (PRP-sol group), and sustained-release form of PRP (100 $\mu \mathrm{l} \mathrm{PRP/10} \mathrm{mg}$ gelatin hydrogel microspheres, PRP-sr group). Treatments were applied by way of a single intramuscular injection to the ischemic site.

At 4 weeks after the initiation of treatment, the mice were reanesthetized using an intraperitoneal injection of pentobarbital $(60 \mathrm{mg} / \mathrm{kg})$, subjected to the measurements described below, and then sacrificed with an overdose of pentobarbital for histological examination.

\section{Measurement of Hind Limb Blood Perfusion}

Hind limb blood perfusion was scanned using a laser Doppler perfusion image (LDPI) analyzer (Moor Instruments, Devon, UK) on the first day of treatment and then every 7 days throughout the whole study period. To eliminate the influence of the surgical procedure, the average blood perfusion of the bilateral feet was evaluated. To minimize influential variables including ambient light and temperature, perfusion was expressed as the ratio of the blood perfusion in the right (ischemic) limb to that in the left (nonischemic) limb of the same mouse, i.e. in terms of the LDPI index (LDPII) $[9,11,16]$.

\section{Immunohistological Analysis}

The immunohistological study was conducted as described previously $[9,11,16]$. Briefly, the mice were euthanized and perfusion-fixed with $4 \%$ paraformaldehyde 4 weeks after the initiation of treatment. The ischemic calf muscles were embedded in OCT compound (Sakura Finetechnical, Tokyo, Japan) and frozen at $-80^{\circ} \mathrm{C}$. Cryostat sections $(5-\mu \mathrm{m}$ thick) of the tissues were stained with rabbit polyclonal anti-human von Willebrand factor (vWF) antibody or mouse monoclonal anti-human smooth muscle actin antibody. As the negative control, rabbit normal immunoglobulin fraction (Dako Japan, Kyoto, Japan) was used to show antibody specificity. From each mouse, 8 random fields on 2 different sections (approximately $3 \mathrm{~mm}$ apart) were photographed with a digital camera (Olympus). The number of vWF (endothelial marker)-positive or SMA (vascular smooth muscle marker)positive vessels was counted manually in a blind fashion (vessels/ $\mathrm{mm}^{2}$ ). Vascular density (angiogenesis) was determined by the counted number of vWF-positive vessels and mature vessel density (arteriogenesis) by the counted number of SMA-positive vessels. 


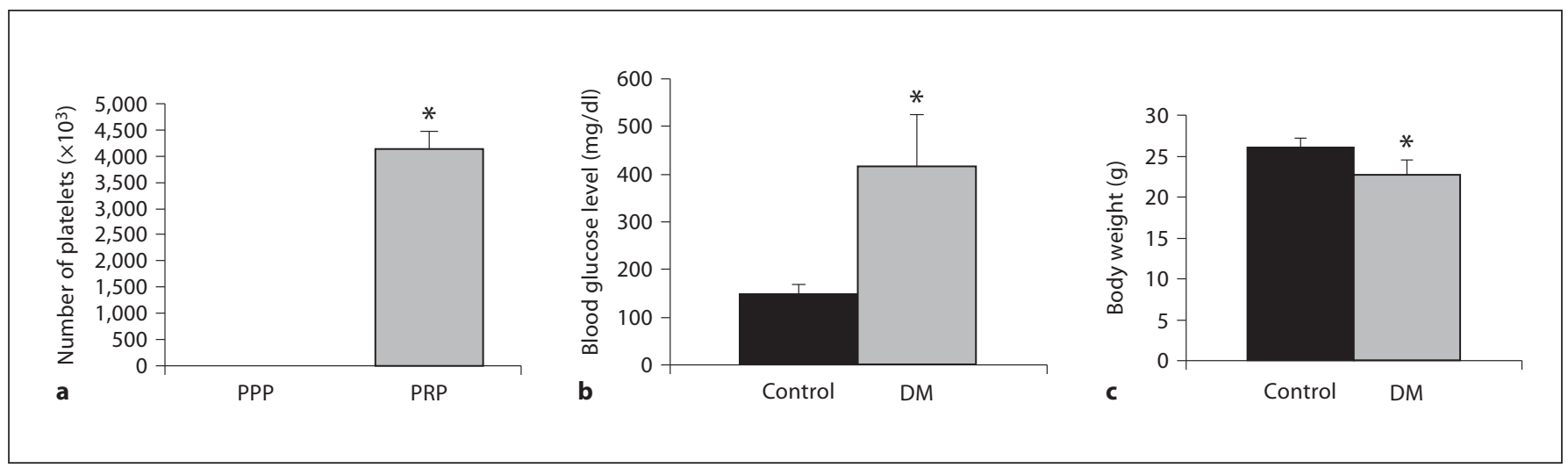

Fig. 1. PRP contains a large number of platelets in a small volume of plasma compared to PPP. a Concentration of platelets in PRP and PPP. * $\mathrm{p}<0.05$ vs. PPP group. b Blood glucose level in diabetic mice compared to nondiabetic mice. ${ }^{*} \mathrm{p}<0.05$ vs. control group (non DM). c Body weight of diabetic mice compared to nondiabetic mice. ${ }^{*} \mathrm{p}<0.05$ vs. control group (non DM).

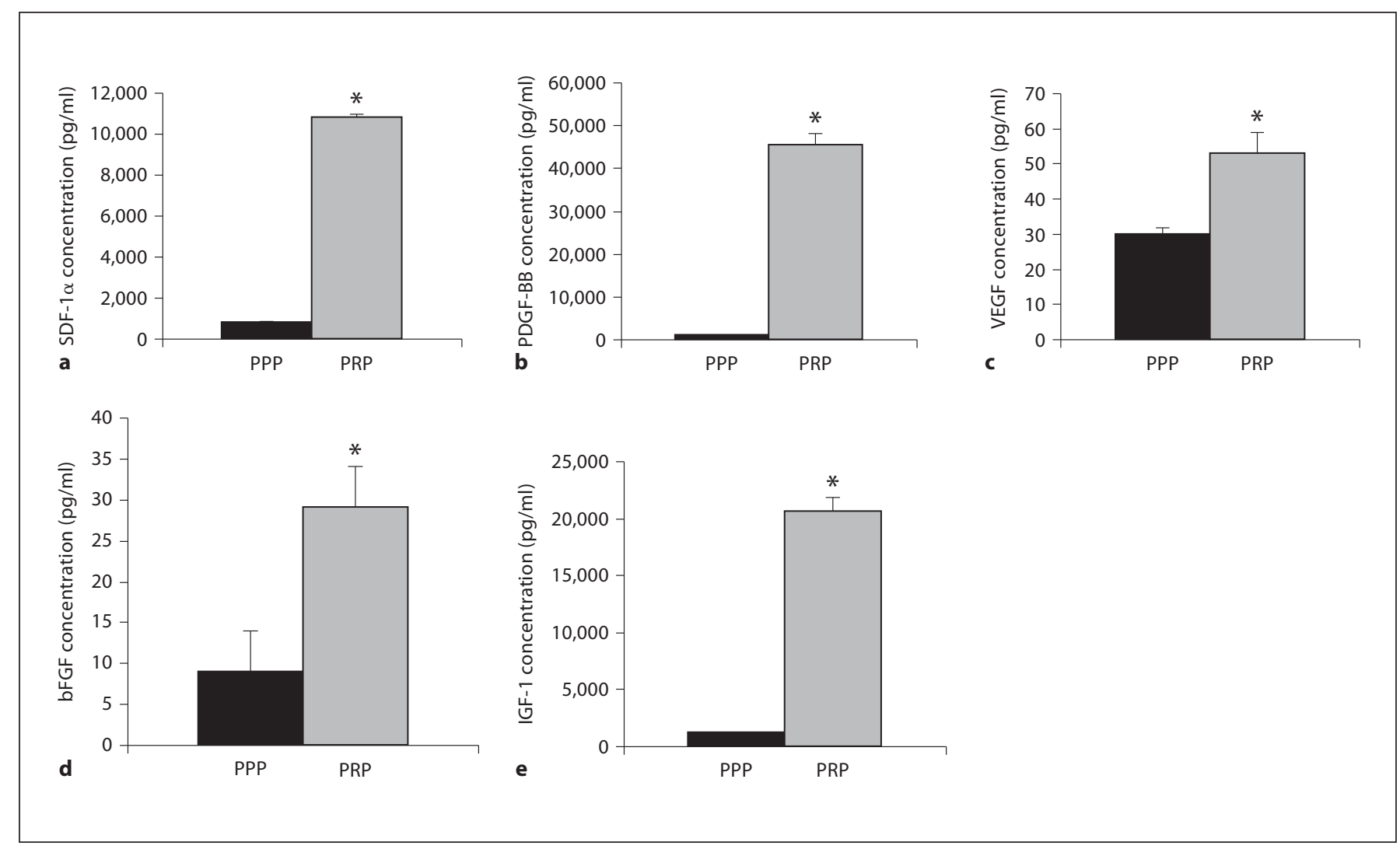

Fig. 2. Concentration of different growth factors in PPP and PRP. $\mathbf{a}$ SDF- $1 \alpha(n=5) \cdot \mathbf{b}$ PDGF-BB $(n=5) \cdot \mathbf{c} V E G F$ $(n=5)$. d bFGF $(n=5)$. e IGF-1 $(n=5) .{ }^{*} p<0.05$ vs. PPP group. 


\section{Results}

\section{Concentration of Platelets in PRP}

Figure 1a shows the platelet concentration in PRP compared to PPP. The number of platelets was higher in the PRP group than that in the PPP group $(4,410 \pm 34 \times$ $10^{3}$ vs. $3.6 \pm 1.1 \times 10^{3}$, respectively; $\left.\mathrm{p}<0.05\right)$

\section{Blood Sugar Level and Body Weight Profile}

Figure $1 \mathrm{~b}, \mathrm{c}$ shows the serum blood sugar level $(\mathrm{mg} / \mathrm{dl})$ and body weight $(\mathrm{g})$ of the DM mice, respectively. The blood sugar level was higher in the DM group compared to the controls (non-DM) $(414 \pm 110$ vs. $146 \pm 23$ for DM and control mice, respectively; $\mathrm{p}<0.05)$. This blood sugar level $(>250 \mathrm{mg} / \mathrm{dl})$ was consistently maintained during the whole study period. In contrast, body weight in the DM mice was significantly lower than in the control mice (26 \pm 1 vs. $23 \pm 2$ for DM mice and controls, respectively; $\mathrm{p}<0.05)$.

\section{Concentration of Different Growth Factors in PRP and $P P P$}

Figure 2 shows the concentration of various growth factors. The concentration $(\mathrm{pg} / \mathrm{ml})$ of different growth factors was significantly higher in the PRP group than in the PPP group. The concentrations $(\mathrm{pg} / \mathrm{ml})$ of SDF- $1 \alpha$ $(10,790 \pm 196$ vs. $810 \pm 39)$, PDGF-BB $(45,352 \pm 2,698$ vs. $958 \pm 251), \operatorname{VEGF}(53 \pm 6$ vs. $30 \pm 2)$, $\operatorname{bFGF}(29 \pm$ 5 vs. $9 \pm 5)$, and IGF-1 (20,628 $\pm 1,180$ vs. $1,214 \pm 36)$ were significantly higher in the PRP group than in the PPP group, respectively.

\section{In vitro Endothelial Cell Proliferation Assay and}

Capillary Tube Formation Assay

Figure 3a shows the time course of endothelial cell proliferation by PRP. Endothelial cell proliferation was induced consistently with PRP from day 1 through day 3. At day 3 , the numbers of endothelial cells was higher in the PRP group than in the control and PPP groups (2.01 $\pm 0.63 \times 10^{4} ; 2.1 \pm 0.19 \times 10^{4}$, and $7.95 \pm 0.64 \times 10^{4}$ for the control, PPP, and PRP groups, respectively; $\mathrm{p}<$ 0.05 ). Figure $3 \mathrm{~b}, \mathrm{~d}$ shows the capillary tube formation by PRP. The capillary tube area $\left(\mu \mathrm{m}^{2}\right)$ was higher in the PRP group than in the controls $(88,567 \pm 9,871$ vs. $39,978 \pm$ $8,522$, respectively; $\mathrm{p}<0.05)$.

\section{Blood Perfusion}

The time course of blood perfusion is depicted in figure 4 . The LDPII in the PRP-sr group was significantly higher than in the other groups 4 weeks after treatment
$(41 \pm 18 ; 57 \pm 14 ; 64 \pm 12$, and $85 \pm 13$ for the control, PPP, PRP-sol, and PRP-sr groups, respectively; $\mathrm{p}<0.05$ ). No significant difference in LDPII was observed among the control, PPP, and PRP-sol groups.

\section{Vascular Density}

Vascular density (stained with anti-vWF antibody) and representative photomicrographs of histological sections are shown in figure $5 \mathrm{a}, \mathrm{b}$, respectively. Vascular density in the PRP-sr group was higher than in the other groups at 4 weeks after the initiation of treatment (141 \pm 29; $131 \pm 37 ; 143 \pm 31$, and $291 \pm 42$ for the control, PPP, PRP-sol, and PRP-sr groups, respectively; $\mathrm{p}<0.05)$. No significant difference in vascular density was observed among the control, PPP, and PRP-sol groups.

\section{Mature Vessel Density}

Mature vessel density (stained with anti-smooth muscle actin antibody) and representative photomicrographs of histological sections are shown in figure 6a, b. Mature vessel density in the PRP-sol and PRP-sr groups was higher than in the other groups at 4 weeks after the initiation of treatment $(33 \pm 17 ; 28 \pm 11 ; 41 \pm 13$, and 92 \pm 12 for the control, PPP, PRP-sol, and PRP-sr groups, respectively; $p<0.05)$. Mature vessel density in the PRPsr group was higher than that in the PRP-sol group. No significant difference in mature vessel density was observed between the control and PPP groups.

\section{Discussion}

\section{Key Findings}

To our knowledge, this is the first study looking at the effect of the sustained release form of PRP on endothelial cell proliferation and capillary tube formation in vitro and the augmentation of blood perfusion in STZ-induced diabetic mouse hind limb ischemia.

Clinically useful strategies for enhancing therapeutic angiogenesis have largely been unrealized. This is likely because stimulation of revascularization involves multiple complex events such as angiogenesis, arteriogenesis, and vasculogenesis. These mechanisms are tightly controlled by several growth factors that favor vessel growth. Single growth factor use has limitations to inducing optimal angiogenesis as such; the establishment of stable and functional blood vessel networks requires several angiogenic factors [1-5].

It has been reported that PRP is a storage vehicle for various growth factors such as PDGF, IGF-1, VEGF, 

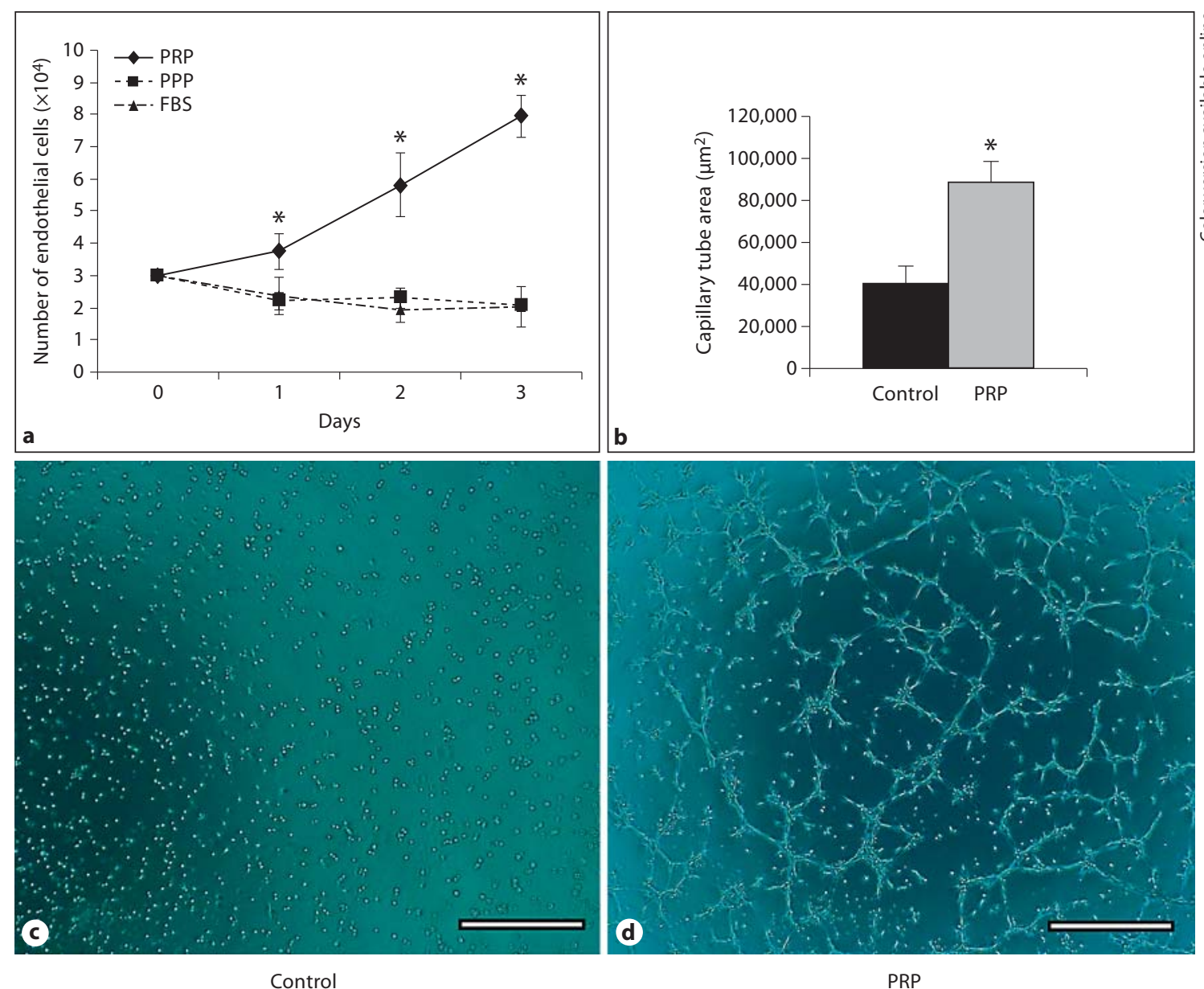

Control

PRP

Fig. 3. PRP induces endothelial cell proliferation. a Time course of endothelial cell proliferation resulting from the control (FBS) $10 \mu \mathrm{l}$, PPP $10 \mu \mathrm{l}$, and PRP $(10 \mu \mathrm{l})$. $\mathbf{b}$ Capillary tube area formed by the control and PRP, $\mathrm{n}=3$ in each group. $\mathbf{c}$, d Photomicrographs of the capillary tube formed by the control (FBS) and PRP. Scale bars = $100 \mu \mathrm{m} .{ }^{*} \mathrm{p}<0.05$ vs. control group.

bFGF, and TGF- $\beta$, among others $[11,12]$. We measured different growth factors in the PRP of STZ-induced diabetic mice and found that PRP contains relatively large amounts of SDF-1 $\alpha$, PDGF-BB, and IGF-1, as well as small amounts of VEGF and bFGF, compared to PPP (fig. 2); this correlates with our previous study [11]. PRP containing angiogenic growth factors affects angiogenesis as well as wound healing $[12,18]$. Platelet-derived microparticles stimulate the proliferation, survival, adhesion, and chemotaxis of hematopoietic cells in vitro [19]. Our findings have shown that the PRP of STZ-induced diabetic mice is capable of stimulating the proliferation of endothelial cells and can also produce an endothelial capillary tube. We reasoned, therefore, that PRP may represent therapeutic intervention that stimulates ischemic angiogenesis with a high efficacy by virtue of providing various potential angiogenic growth factors in mouse hind limb ischemia.

It has been recognized that platelets in PRP secrete various growth factors during the degranulation of $\alpha$ granules and that the secreted factors exhibit various biologic activities. It is well known that collagen and thrombin trigger platelet aggregation and the subsequent secretion of platelet growth factors [17]. Gelatin, a derivative of collagen, can also trigger platelet activation for growth factor secretion which is similar to that of thrombin [14, 17]. Our previous studies have shown that when platelets in PRP are activated with gelatin molecules during the process of PRP impregnation, growth factors are released from the PRP. The growth factors secreted are immobi- 

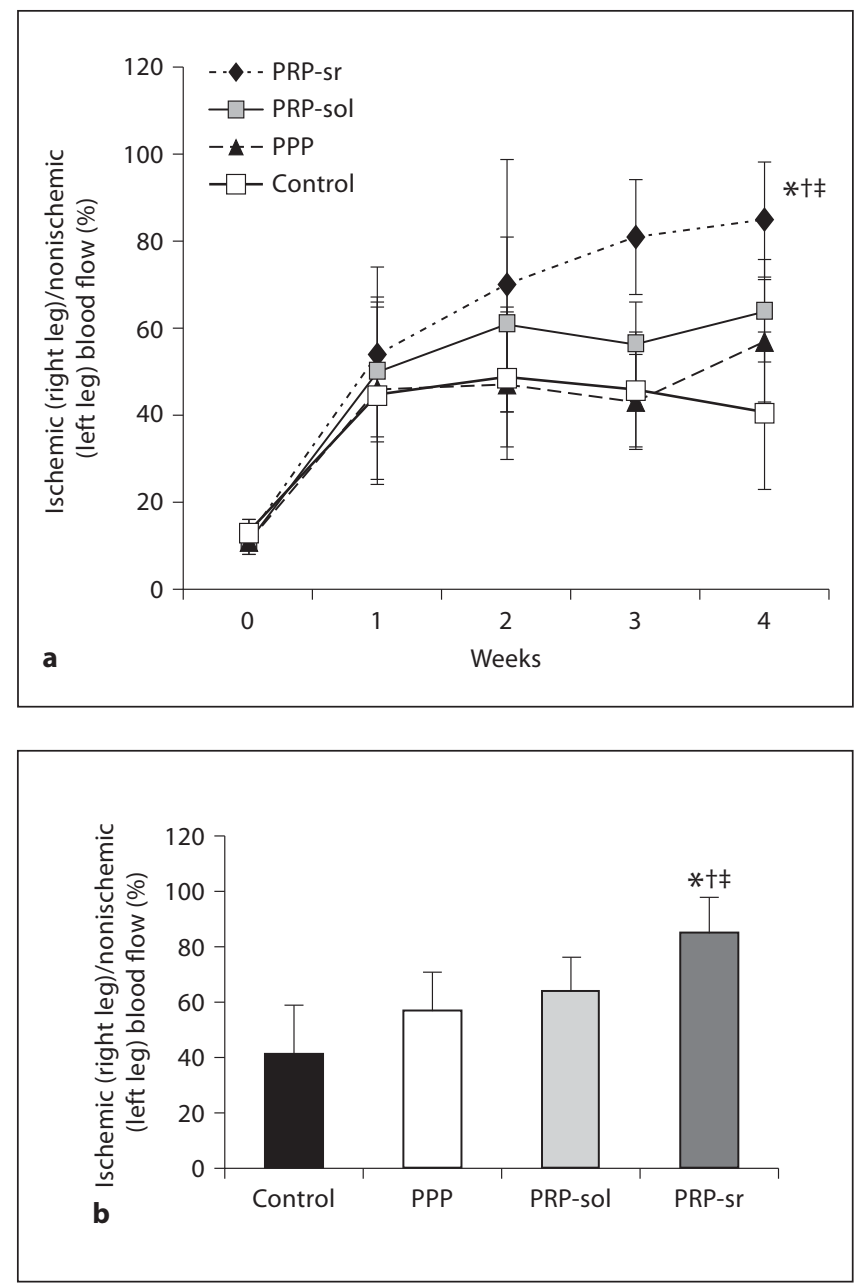

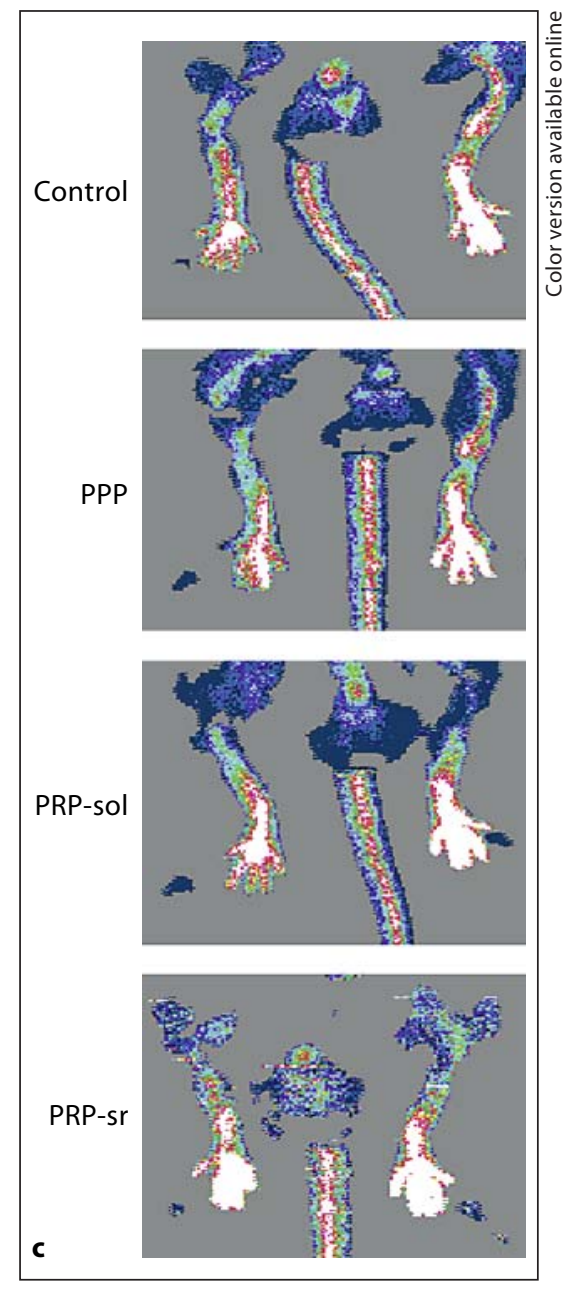

Fig. 4. a Time course of the ischemic (right leg)/nonischemic (left leg) blood perfusion ratio (\%) in the different groups of mice with various treatments. $\mathbf{b}$ Ischemic/nonischemic blood perfusion ratio in the different groups at 4 weeks after various treatments. c LDPI in the different groups. Control group = Gelatin; PPP group = treatment with $100 \mu \mathrm{lPP}$; PRP-sol group = treatment with the solution form of $100 \mu l$ PRP; PRP-sr group $=$ treatment with the sustained-release form of $100 \mu \mathrm{l}$ PRP; $n=10$ in each group. ${ }^{*} \mathrm{p}<0.05$ vs. control group; ${ }^{\dagger} \mathrm{p}<0.05$ vs. PPP group; ${ }^{\ddagger} \mathrm{p}<0.05$ vs. PRP-sol group.

lized in the hydrogel through physicochemical interaction with gelatin molecules. The immobilized growth factors are released from the hydrogel as a result of hydrogel degradation $[11,17]$. Therefore, we used gelatin hydrogel as a carrier for the growth factors in PRP.

Diabetes impairs neovascularization processes such as angiogenesis, arteriogenesis, and vasculogenesis [6-10]. In contrast, the successful reperfusion of ischemic tissue depends on complex events of neovascularization which require interplay between cells and angiogenic growth factors. For example, endothelial cells, whether preexisting or progenitor, smooth muscle cells, and pericytes are required to form complete stable vessels. VEGF causes endothelial cell proliferation and migration which result in capillary sprouting or angiogenesis. VEGF also promotes mural cell accumulation presumably through the release of PDGF-BB. Basic FGF and PDGF are chemoattractants used to smooth muscle cells. Those are also causes of the growth of smooth muscle cells as well as the enlargement of the vessel (formation of mature vessels or arteriogenesis). VEGF and SDF-1 recruit hematopoietic stem cells to the ischemic site from bone marrow via circulation. These stem cells produce capillary plexuses and eventually form mature vessels. All together, they cause 


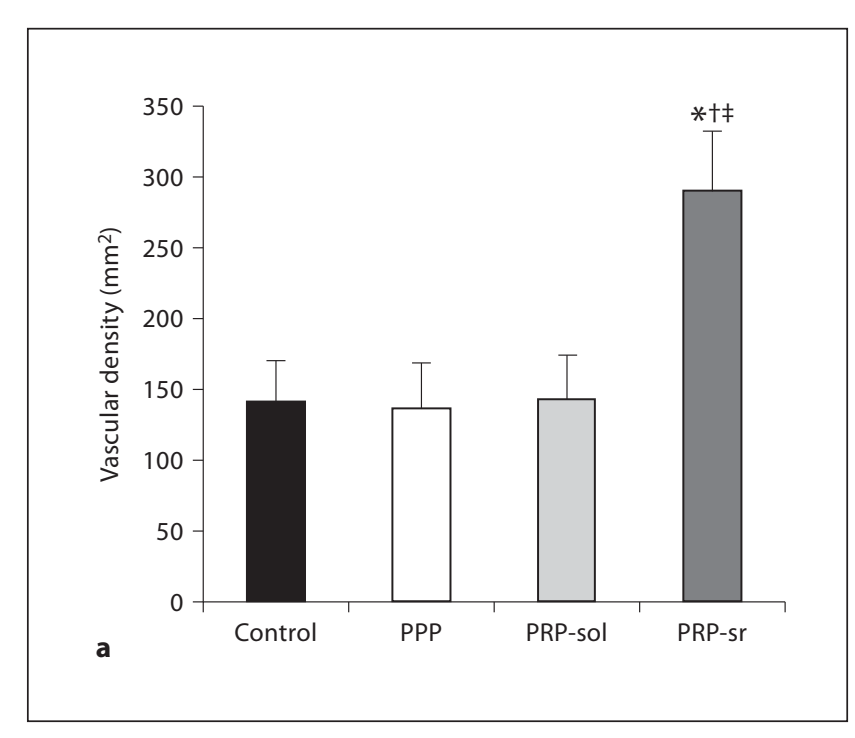

Fig. 5. a Vascular density in the ischemic calf muscles stained with anti-human vWF at 4 weeks after surgery. b Representative photomicrographs of the ischemic calf muscles single stained (diaminobenzene) with anti-human vWF at 4 weeks after surgery. Scale bars $=100 \mu \mathrm{m}$. Control group = Gelatin; $\mathrm{PPP}$ group = treatment with $100 \mu \mathrm{lPP}$; PRP-sol group = treatment with the solution form of $100 \mu \mathrm{l} \mathrm{PRP;} \mathrm{PRP-sr}$ group $=$ treatment with the sustained-release form of $100 \mu \mathrm{l}$ PRP; $\mathrm{n}=10$ in each group. ${ }^{*} \mathrm{p}<0.05$ vs. control group; ${ }^{\dagger} \mathrm{p}<$ 0.05 vs. PPP group; ${ }^{\ddagger} \mathrm{p}<0.05$ vs. PRP-sol group.

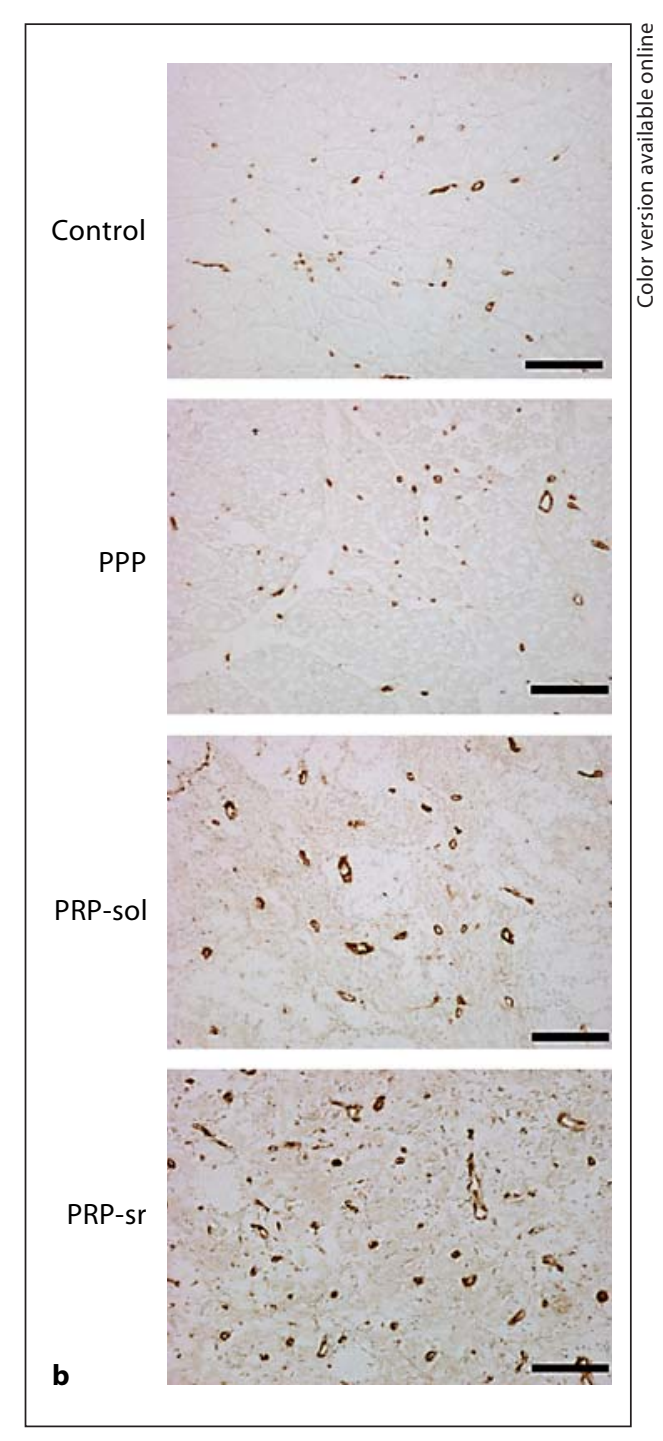

the genesis of new vessels for vascular supply in ischemic limbs [3-5]. Therefore, the coadministration of different growth factors may result in well organized neovascularization useful for therapeutic application in diabetes [4].

Langer and Gawaz [20] have suggested that platelets are important participants in tissue repair by interaction with progenitor cells. Moreover, they can exert regenerative effects themselves although they promote proinflammatory processes. This study shows that STZ-induced diabetic PRP contains large amounts of different growth factors which cause endothelial cell proliferation and capillary tube formation in vitro. Nonetheless, our previous study has shown that PRP augments ischemic neovascularization presumably due to the stimulation of angiogenesis, arteriogenesis, and vasculogenesis [11].

\section{Diabetic Ischemia, Angiogenesis, and the Effect of PRP}

VEGF is the principle stimulatory factor of angiogenesis after ischemia [21,22], but research-based evidence has shown that bFGF, IGF-1, and SDF-1 can induce angiogenesis via direct or indirect stimulation [23-25]. Angiogenesis is impaired in diabetes due to a decrease in VEGF protein and its receptor expression, and this can be rescued by the external induction of VEGF protein [6]. Our recent and previous study showed that PRP contains a higher concentration of VEGF, bFGF, SDF-1, and IGF-1 than does PPP, which might contribute to angiogenesis in the diabetic hind limb ischemia model [11]. However, VEGF by itself promotes the formation of leaky, unstable capillaries rather than arteriogenesis, which leads us to 

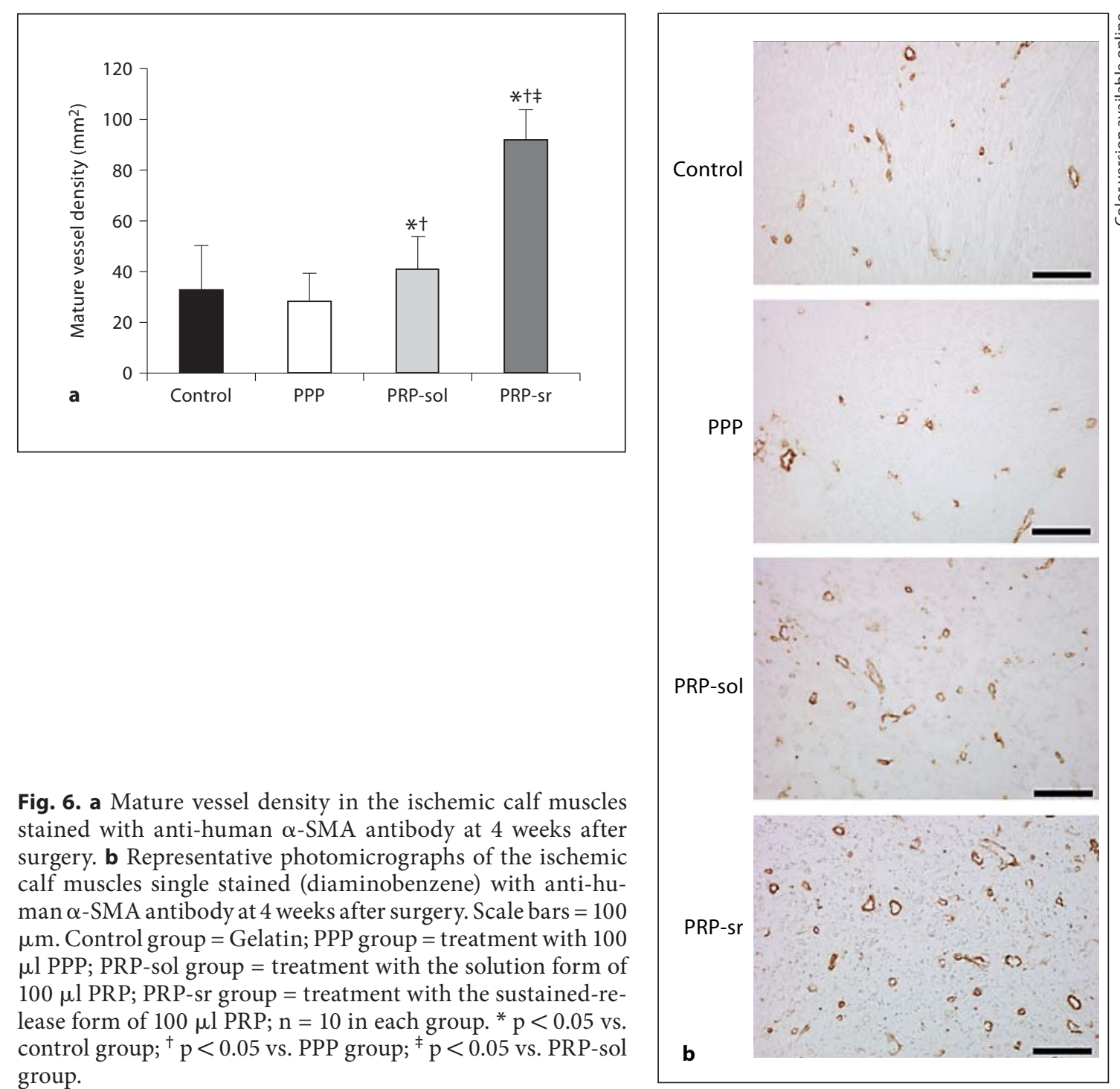

Fig. 6. a Mature vessel density in the ischemic calf muscles stained with anti-human $\alpha$-SMA antibody at 4 weeks after surgery. $\mathbf{b}$ Representative photomicrographs of the ischemic calf muscles single stained (diaminobenzene) with anti-human $\alpha$-SMA antibody at 4 weeks after surgery. Scale bars $=100$ $\mu \mathrm{m}$. Control group = Gelatin; PPP group = treatment with 100 $\mu l$ PPP; PRP-sol group = treatment with the solution form of $100 \mu l$ PRP; PRP-sr group = treatment with the sustained-release form of $100 \mu \mathrm{l}$ PRP; $\mathrm{n}=10$ in each group. ${ }^{*} \mathrm{p}<0.05$ vs. control group; ${ }^{\dagger} \mathrm{p}<0.05$ vs. PPP group; ${ }^{\ddagger} \mathrm{p}<0.05$ vs. PRP-sol group.

the coadministration of different growth factors for neovascularization in diabetic ischemia [4].

\section{Diabetic Ischemia, Arteriogenesis, and the Effect of PRP}

Arteriogenesis is the principle driver of the restoration of blood perfusion in the ischemic neovascularization of diabetes as well as in hypercholesterolemic models. There is strong evidence from both clinical and basic research studies, including our previous study, that arteriogenesis is severely impaired in diabetic ischemia [7-9]. Basic FGF and PDGF have strong arteriogenic effects $[4,9,23,26$, 27]. Langer and Gawaz [20] have showed that platelets substantially recruit mesenchymal stem cells to the al- tered vascular wall and enhance biological functions such as proliferation, migration, and endothelial integration of mesenchymal stem cells [28]. Besides these, there is strong evidence that the expression of PDGF is impaired and there is a slight reduction of the expression of bFGF at the ischemic site of the diabetic model [29]. However, PRP contains large amounts of PDGF-BB and bFGF which could stimulate arteriogenesis in diabetic ischemia.

There is also cross talk between VEGF and bFGF and between $\mathrm{bFGF}$ and PDGF-BB to induce angiogenesis after ischemia [4, 29-32]. Our findings have shown that PRP effectively restores blood flow via a significant augmentation of the number of capillaries (angiogenesis) as well as mature vessels (arteriogenesis) in mouse hind 
limb ischemia (fig 5, 6). Moreover, the sustained release form of PRP showed a higher effect compare to the solution form. The sustained release of PRP showed a restoration of blood flow (about 90\%) within 4 weeks of treatment; while in this study we did not clarify the individual role of growth factors and signaling mechanisms of angiogenesis related to PRP in diabetes, some authors suggested that PRP acts via a concerted action of different growth factors to stimulate angiogenesis and postischemic revascularization [33].

\section{Diabetic Ischemia, Vasculogenesis, and the Effect} of PRP

Vasculogenesis is one of the predictor mechanisms of neovascularization [34]. However, there is strong evidence that vasculogenesis is impaired in diabetic ischemia [10]. It has already been reported that EPC recruitment and homing are guided by SDF-1 and VEGF. Asahara et al. [35] showed that VEGF contributes to postnatal neovascularization by mobilizing bone marrow-derived endothelial progenitor cells. SDF-1 regulates the mobilization and local trafficking of progenitor cells to the ischemic site. De Falco et al. [36] also suggested that the transient establishment of SDF-1 favors stem cell translocation into ischemic tissue, thereby enhancing neovascularization [37]. Our data reflects that PRP contains a small amount of VEGF and a relatively large amount of SDF-1 $\alpha$. Massberg et al. [38] suggested that platelets secrete SDF- $1 \alpha$ and recruit bone marrow-derived progenitor cells to the injured arterial site. Our previous study also showed that the sustained release of PRP accelerates the homing of hematopoietic progenitor cells to the ischemic site in vivo which reflects the contribution of the sustained release of PRP to vasculogenesis in hind limb ischemia [11]. Therefore, SDF-1 and VEGF in PRP might contribute to reverse the impaired vasculogenesis effect in diabetic ischemia.

\section{Clinical Relevance}

PRP is a natural, cost-effective reservoir of various growth factors which can be collected autologously. Thus, for clinical use, no special considerations concerning antibody formation and infection risk are needed. Some clinical devices to automatically prepare PRP are currently available. PRP have been consistently used in clinical settings in departments of orthopedics and plastic surgery (oral and maxillary facial) over many years [3940]. Based on research evidence, some publications have reported positive results of PRP in either bone or soft tissue healing, yet other studies have concluded little-to-no benefit of PRP. This is likely due to the rapid degradation of growth factors in PRP since some studies suggest using sustained-release forms of PRP to achieve optimal effects. Gelatin hydrogel is used clinically as a slow, sustained release of carrier for growth factors and may be beneficial for enhancing PRP therapy.

\section{Concluding Remarks}

The sustained release of PRP using gelatin hydrogel can be a highly potent and effective modality for restoring blood perfusion to diabetic mouse hind limb ischemia. This is because the sustained release of PRP stimulates all possible aspects of impaired vascular remodeling in diabetes, such as angiogenesis, arteriogenesis and vasculogenesis, in addition to being very cost effective, autologus, and safe. These may be applicable in the clinical setting in diabetic patients with CLI.

\section{Acknowledgements}

The authors would like to thank Fumiyo Kataoka, Mari Ishii, and Maiko Yamamoto (Kyoto University) for their kind secretarial assistance. This study was presented at Scientific Sessions 2008 of the American Heart Association.
References
1 Tirziu D, Simons M: Angiogenesis in the human heart: gene and cell therapy. Angiogenesis 2005;8:241-251.

-2 Carmeliet P, Conway EM: Growing better blood vessels. Nat Biotechnol 2001;19:10191020.

- 3 Ferrara N, Alitalo K: Clinical applications of angiogenic growth factors and their inhibitors. Nat Med 1999;5:135-164.

-4 Cao R, Brakenhielm E, Pawliuk R, Wariaro D, Post MJ, Wahlberg E, Cao Y: Angiogenic synergism, vascular stability and improve- ment of hind-limb ischemia by a combination of PDGF-BB and FGF-2. Nat Med 2003 9:604-613.

5 Carmeliet P: Mechanisms of angiogenesis and arteriogenesis. Nat Med 2000;6:389395.

6 Rivard A, Silver M, Chen D, Kearney M, Magner M, Annex B, Peters K, Isner JM: Rescue of diabetes-related impairment of angiogenesis by intramuscular gene therapy with adeno-VEGF. Am J Pathol 1999;154:355363. 
-7 Abaci A, Oguzhan A, Kahraman S, Eryol NK, Unal S, Arinc H, Ergin A: Effects of diabetes on formation of coronary collateral vessels. Circulation 1999;99:2239-2242.

$>8$ Weihrauch D, Lohr NL, Mraovic B, Ludwig LM, Chilian WM, Pagel PS, Warltier DC, Kersten JR: Chronic hyperglycemia attenuates coronary collateral development and impairs proliferative properties of myocardial interstitial fluid by production of angiostatin. Circulation 2004;109:2343-2348.

9 Bir SC, Fujita M, Marui A, Hirose K, Arai Y, Sakaguchi H, Huang Y, Esaki J, Ikeda T, Tabata Y, Komeda M: New therapeutic approach for impaired arteriogenesis in diabetic mouse hind limb ischemia. Circ J 2008;74: 633-640.

10 Waltenberger J: Impaired collateral vessels development in diabetes: potential cellular mechanism and therapeutic implications. Cardiovasc Res 2001;49:554-560.

-11 Bir SC, Esaki J, Marui A, Yamahara K, Tsubota H, Ikeda T, Sakata R: Angiogenic properties of sustained release platelet-rich plasma: characterization in-vitro and in the ischemic hind limb of the mouse. J Vasc Surg 2009;50:870-879.

-12 Frechette JP, Martineau I, Gagnon G: Platelet-rich plasmas: growth factor content and roles in wound healing. J Dent Res 2005;84: 434-439.

-13 Dugrillon A, Eichler H, Kern S, Kluter H: Autologous concentrated platelet-rich plasma (cPRP) for local application in bone regeneration. Int J Oral Maxillofac Surg 2002; 31:615-619.

14 Marx RE: Platelet-rich plasma: evidence to support its use. J Oral Maxillofac Surg 2004; 62:489-496.

15 Tabata Y: Tissue regeneration based on growth factor release. Tissue Eng 2003;9:515.

-16 Marui A, Kanemitsu A, Yamahara K, Doi K, Kushibiki T, Yamamoto M, Itoh H, Ikeda T, Tabata Y, Komeda M: Simultaneous application of basic fibroblast growth factor and hepatocyte growth factor to enhance the blood vessels formation. J Vasc Surg 2005;41:8290.

- 17 Hokugo A, Ozeki M, Kawakami O, Sugimoto K, Mushimoto K, Morita S, Tabata Y: Augmented bone regeneration activity of platelet-rich plasma by biodegradable gelatin hydrogel. Tissue Eng 2005;11:1224-1233.

-18 Gandhi A, Doumas C, O’Connor JP, Parsons JR, Lin SS: The effects of local platelet rich plasma delivery on diabetic fracture healing. Bone 2006;38:540-546.

>19 Baj-Krzyworzeka M, Majka M, Pratico D: Platelet-derived microparticles stimulate proliferation, survival, adhesion, and chemotaxis of hematopoietic cells. Exp Hematol 2002;30:450-459.
20 Langer HF, Gawaz M: Platelets in regenerative medicine. Basic Res Cardiol 2008;103. 299-230.

21 Yancopoulos GD, Davis S, Gale NW, Rudge JS, Wiegand SJ, Holash J: Vascular specific growth factors and blood vessel formation. Nature 2000;407:242-248.

22 Ferrara N, Gerber HP: Role of vascular endothelial growth factor in angiogenesis. Acta Haematol 2001;106:148-156.

23 Hosaka A, Koyama H, Kushibiki T, Tabata Y, Nishiyama N, Miyata T, Shigematsu H, Takato T, Nagawa H: Gelatin hydrogel microspheres enable pinpoint delivery of basic fibroblast growth factor for the development of functional collaterals. Circulation 2004; 110:3322-3328.

24 Kanemitsue N, Tambara K, Premaratne GU, Kimura Y, Tomita S, Kawamura T, Hasegawa $\mathrm{K}$, Tabata Y, Komeda M: Insulin-like growth factor-1 enhances the efficacy of myoblast transplantation with its multiple functions in the chronic myocardial infarction rat model. J Heart Lung Transplant 2006;25: 1253-1262.

25 Yamaguchi J, Kusano KF, Masou O, Kawamoto A, Silver M, Murasawa S, Bosch-Marce M, Masuda H, Losordo DW, Isner JM, Asahara T: Stromal cell-derived factor-1 effects on ex vivo expanded endothelial progenitor cell recruitment for ischemic neovascularization. Circulation 2003;107:1322-1328.

26 Helisch A, Schaper W: Arteriogenesis: the development and growth of collateral arteries. Microcirculation 2003;10:83-97.

27 van Royen N, Piek JJ, Buchmann I, Hoefer I, Voskuil M, Schaper W: Stimulation of arteriogenesis: a new concept for the treatment of arterial occlusive disease. Cardivasc Res 2001;49:543-553.

28 Langer HF, Stellos K, Steingen C, Froihofer A, Schönberger T, Krämer B, Bigalke B, May AE, Seizer P, Müller I, Gieseke F, Siegel-Axel D, Meuth SG, Schmidt A, Wendel HP, Müller I, Bloch W, Gawaz M: Platelet derived bFGF mediates vascular integrative mechanisms of mesenchymal stem cells in vitro. J Mol Cell Cardiol 2009;47:315-325.

-29 Tanii M, Yonemitsu Y, Fujii T, Shikada Y, Kohno R, Onimaru M, Okano S, Inoue M, Hasegawa M, Onohara T, Maehara Y, Sueishi $\mathrm{K}$ : Diabetic microangiopathy in ischemic limb is a disease of disturbance of the platelet-derived growth factor-BB/protein kinase $\mathrm{C}$ axis but not of impaired expression of angiogenic factors. Circ Res 2006;98:55-62.

30 Asahara T, Bauters C, Zheng LP, Takeshita S, Bunting S, Ferrara N, Symes JF, Isner JM Synergistic effect of vascular endothelial growth factor and basic fibroblast growth factor on angiogenesis in vivo. Circulation 1995;92:365-371.
31 Layman H, Sacasa M, Murphy AE, Murphy AM, Pham SM, Andreopoulos FM: Co-delivery of FGF-2 and G-CSF from gelatinbased hydrogels as angiogenic therapy in a murine critical limb ischemic model. Acta Biomater 2009;5:230-239.

>32 Hughes GC, Biswas SS, Yin B, Coleman RE, DeGrado TR, Landolfo CK, Lowe JE, Annex $\mathrm{BH}$, Landolfo KP: Therapeutic angiogenesis in chronically ischemic porcine myocardium: comparative effects of bFGF and VEGF. Ann Thorac Surg 2004;77:812-818.

33 Brill A, Dashevsky O, Rivo J, Gozal Y, Varon D: Platelet-derived microparticles induce angiogenesis and stimulate post-ischemic revascularization. Cardiovasc Res 2005;67: 30-38.

34 Tepper OM, Calpa JM, Galiano RD, Ceradini DJ, Callaghan MJ, Kleinman ME, Gurtner GC: Adult vasculogenesis occurs through in situ recruitment, proliferation, and tubulization of circulating bone marrow-derived cells. Blood 2005; 105:1068-1077.

35 Asahara T, Takahashi T, Masuda H, Kalka C, Chen D, Iwaguro H, Inai Y, Silver M, Isner JM: VEGF contributes to postnatal neovascularization by mobilizing bone marrow-derived endothelial progenitor cells. EMBO J 1999; 18:3964-3972.

-36 De Falco E, Porcelli D, Torella AR, Straino S, Iachininoto MG, Orlandi A, Truffa S, Biglioli P, Napolitano M, Capogrossi MC, Pesce M: SDF-1 involvement in endothelial phenotype and ischemia-induced recruitment of bone marrow progenitor cells. Blood 2004; 104:3472-3482

37 Stellos K, Langer H, Daub K, Schoenberger T, Gauss A, Geisler T, Bigalke B, Mueller I, Schumm M, Schaefer I, Seizer P, Kraemer BF, Siegel-Axel D, May AE, Lindemann S, Gawaz M: Platelet-derived stromal cell-derived factor- 1 regulates adhesion and promotes differentiation of human CD34+ cells to endothelial progenitor cells. Circulatuion 2008; 117:206-215

- 38 Massberg S, Konrad I, Schürzinger K, Lorenz M, Schneider S, Zohlnhoefer D, Hoppe K, Schiemann M, Kennerknecht E, Sauer S, Schulz C, Kerstan S, Rudelius M, Seidl S, Sorge F, Langer H, Peluso M, Goyal P, Vestweber D, Emambokus NR, Busch DH, Frampton J, Gawaz M: Platelets secrete stromal cell-derived factor lalpha and recruit bone marrow-derived progenitor cells to arterial thrombi in vivo. J Exp Med 2006;203: 1221-1233.

39 Man D, Plosker H, Winland-Brown JF: The use of autologous platelet-rich plasma (platelet gel) and autologous platelet-poor plasma (fibrin glue) in cosmetic surgery. Plast Reconstr Surg 2001;107:229-237.

-40 Tozum TF, Demiralp B: Platelet-rich plasma: a promising innovation in dentistry. J Can Dent Assoc 2003;69:664. 